\title{
DESAFIOS E POTENCIALIDADES NO DEBATE DE GÊNERO E SEXUALIDADE: uma revisão integrativa
}

DOI: 10.22289/2446-922X.V7N2A10

\author{
Antonio Guilherme Martins \\ Maria Eduarda Silva Siqueira da Luz \\ Francisco Jander de Sousa Nogueira ${ }^{1}$
}

\section{RESUMO}

As questões de gênero e sexualidade perpassam as relações das gerações, tornando-se dimensões organizadoras das relações sociais, o que corrobora para a existência de desigualdades, transformada pelas mais variadas culturas e sociedades. Nesse sentido, o artigo teve por objetivo expor sobre os desafios e potencialidades acerca das questões de gênero e sexualidade nos últimos 10 anos, no que diz respeito a saúde e educação no contexto atual. Realizou-se um levantamento da literatura, buscando documentos indexados em sites eletrônicos: SCIELO (Scientific Electronic Library Online), BVS (Biblioteca Nacional de Saúde), LILACS (Literatura Latino-americana e do Caribe em Ciências da Saúde) com os descritores: Gênero e Sexualidade; Gênero e Saúde. Buscou-se documentos que abordassem essas questões utilizando os seguintes critérios de inclusão: livros, teses, artigos e outros tipos de publicações que trabalhassem o tema, publicados entre os anos de 2009 e 2019, listados nas bases de dados referenciados, no idioma Português. Foram encontrados 135 artigos dos quais 11 atenderam aos critérios de inclusão e constituíram a amostra. Os resultados ressaltaram que ainda existem inúmeros entraves relacionados aos direitos e garantias das relações de gênero na saúde e educação. As evidências encontradas nesta revisão indicam a necessidade do debate de gênero dentro das instituições de ensino, o que passa a ser um papel crucial para o enfrentamento das desigualdades, corroborando para a construção de potencialidades significativas na inserção desse discurso na sociedade.

Palavras-chave: Políticas públicas; Escola; Educação em saúde.

\section{CHALLENGES AND POTENTIALITIES IN THE GENDER AND SEXUALITY DEBATE: an integrative review}

\section{ABSTRACT}

The matter of gender and sexuality permeate the relations of generations, making these dimensions organizers of social relations, which confirms the existence of inequalities. In this sense, the article aimed to expose the challenges and potential regarding gender and sexuality issues in the last 10 years, regarding health and education in the current context. Thereby, a literature survey was carried out, looking for documents indexed in electronic sites: SCIELO (Scientific Electronic Library Online), BVS (National Health Library), LILACS (Latin American and Caribbean Literature in Health Sciences) with the descriptors: Gender and Sexuality; Gender and Health. Thus, documents that addressed these issues were sought using the following inclusion

\footnotetext{
${ }^{1}$ Endereço eletrônico de contato: jander.sociosaude@gmail.com

Recebido em 13/06/2021. Aprovado pelo conselho editorial para publicação em 06/09/2021.
}

Rev. Psicol Saúde e Debate. Ago., 2021:7(2): 151-168. 
criteria: books, theses, articles and other types of publications that worked on the theme, published between 2009 and 2019, listed in the referenced databases, in the Portuguese language. From that, 135 articles were found, of which 11 met the inclusion criteria and constituted the sample. The results highlighted that there are still numerous obstacles related to the rights and guarantees of gender relations in health and education. Therefore, the evidence found in this review indicates the need for a gender debate within educational institutions, which becomes a crucial role in confronting inequalities, supporting the construction of significant potential in the insertion of this discussion in society.

Keywords: Public policy; school; health education.

\section{RETOS Y POTENCIALIDADES EN EL DEBATE DE GÉNERO Y SEXUALIDAD: una revisión integradora}

\section{RESUMEN}

Temas de género y sexualidad impregnan las relaciones de generaciones, convirtiéndose en dimensiones organizadoras de las relaciones sociales, lo que corrobora la existencia de desigualdades, transformadas por las más variadas culturas y sociedades. En este sentido, el artículo tuvo como objetivo exponer los desafíos y potencialidades en materia de género y sexualidad en los últimos 10 años, en materia de salud y educación en el contexto actual. Se realizó una encuesta bibliográfica, buscando documentos indexados en sitios electrónicos: SCIELO (Biblioteca Electrónica Científica en Línea), BVS (Biblioteca Nacional de Salud), LILACS (Literatura Latinoamericana y del Caribe en Ciencias de la Salud) con los descriptores: Género y Sexualidad; Género y salud. Se buscaron documentos que abordan estos temas con los siguientes criterios de inclusión: libros, tesis, artículos y otro tipo de publicaciones que trabajaron sobre el tema, publicados entre 2009 y 2019, listados en las bases de datos referenciadas, en idioma portugués. Se encontraron 135 artículos, de los cuales 11 cumplieron los criterios de inclusión y constituyeron la muestra. Los resultados destacaron que aún existen numerosos obstáculos relacionados con los derechos y garantías de las relaciones de género en la salud y la educación. La evidencia encontrada en esta revisión indica la necesidad de un debate de género al interior de las instituciones educativas, que se convierte en un rol crucial en el enfrentamiento de las desigualdades, apoyando la construcción de un potencial significativo en la inserción de este discurso en la sociedad.

Palabras clave: Políticas públicas; colegio; educación para la salud.

\section{INTRODUÇÃO}

Gênero é entendido, de acordo com Scott (1996), como os processos culturais que atuam mediante relações de poder, construindo padrões hegemônicos, a partir de corpos sexuados. Ou seja, com valores históricos, sociais e culturais construídos. Evidencia-se assim, que essas questões perpassam as relações das gerações, 
tornando-se dimensões organizadoras das relações sociais, o que corrobora para a existência de desigualdades, transformadas pelas mais variadas culturas e sociedades.

Diante da complexidade que esse tema remete, é complicado discutir sobre tal assunto, que já possui conceitos sociais, morais e religiosos pré-estabelecidos, sem ir de encontro a esses, assim, limitando a forma de como esse seria trabalhado dentro do campo educacional e da saúde. Sendo que, segundo o volume 10.2, intitulado Orientação Sexual, dos Parâmetros Curriculares Nacionais (Brasil, 1997), a sexualidade é entendida como algo inerente, que se manifesta desde o nascimento à morte, desenvolvendo e construindo ao longo da vida. Dessa forma, destacando a importância de se debater sexualidade e gênero, de forma livre, nesses ambientes.

Além disso, Ferraz, Addor e Neto (2019) afirmam que a maioria das críticas voltadas às discussões de movimentos que trabalhem gênero na educação se baseiam em argumentos falaciosos construídos para deslegitimar um movimento sério teóricoprático que busca a discussão das principais mazelas que afetam boa parte da sociedade, visto que esse tipo de fala se apresenta como causa para o desenvolvimento de preconceitos e discriminações. Destaca-se a importância das políticas públicas educacionais como forma de desconstrução dessas ideias, reconstruindo a forma como esse assunto deve ser tratado no âmbito escolar.

Ademais, se percebe a necessidade da presença do discurso sobre gênero e sexualidade no âmbito da saúde, em que a cisheteronormatividade ainda se sobrepõe, negligenciando indivíduos cujos corpos e identidades diferem da norma, salientando aqui também a necessidade do desenvolvimento das políticas públicas de saúde voltados para esses temas, pois, dessa forma, pode-se reconhecer a variedade das vivências da população e promover o acolhimento de suas demandas, o que permitiria uma melhor expressividade do direito à pluralidade de gênero(Gomes, Murta, Fachini, \& Menehhel, 2018).

Logo, existem diversas formas de adaptar o sistema escolar para abordar os temas de gênero e sexualidade, o que deve ocorrer através das políticas públicas, porém o que se percebe é a influência desses preconceitos na formação dessas políticas. Dessa maneira, como aponta Ivan (2017), esta situação impõe a nós, educadores/as, pesquisadores/as assumirmos a resistência e a defesa da produção de conhecimentos que se contraponham aos discursos do senso comum ou enviesados política e teoricamente.

Rev. Psicol Saúde e Debate. Ago., 2021:7(2): 151-168. 
Para mais, direciona-se mais as discussões sobre gênero e sexualidade às minorias sociais, por exemplo, mulheres, negros, população LGBTQIA+, etc. Isso porque, são vistas por alguns como pessoas ilegítimas para reivindicar seus direitos como cidadãos, contribuindo para o fato dessa parcela da população ser discriminada e possuir pouco poder de voz. Por isso, uma das questões levantadas aqui é que os serviços públicos da educação e da saúde devem buscar formas democráticas para oferecer a tarefa de maneira equitativa, o que só se torna possível através das políticas públicas, pois elas têm, o intuito de democratizar o acesso à educação e a redução do preconceito e da discriminação, garantindo o amplo desenvolvimento da sociedade. (Ferraz, Addor, \& Neto, 2018)

Assim, o presente artigo tem como objetivo expor sobre os desafios e potencialidades da abordagem de questões de gênero e sexualidade no contexto da saúde e da educação. A proposta consistiu em uma revisão integrativa da literatura acerca dos estudos da implementação desse debate dentro do âmbito escolar, sendo esse o principal questionamento, discutindo através deste a aplicação das políticas públicas de educação e de gênero.

\section{MÉTODO}

Trata-se de um estudo realizado com base em seis etapas estabelecidas inicialmente para uma melhor formulação da revisão, tais como: elaboração da questão norteadora da pesquisa; delineamento dos métodos de seleção dos estudos; extração de dados para o procedimento da pesquisa; avaliação dos estudos encontrados nas bases de dados; detalhamento dos dados pesquisados e síntese do conhecimento produzido e publicado.

Dessa maneira, de acordo com os critérios para uma melhor fundamentação teórica e científica, a presente revisão teve como questão norteadora: Quais os desafios e potencialidades no debate de gênero e sexualidade enfrentados no tocante à promoção da saúde sexual? Para melhor abordagem dessa questão, realizou-se um levantamento da literatura no dia 05 de abril de 2020, buscando publicações indexadas nas bases de dados: SCIELO (Scientific Electronic Library Online), LILACS (Literatura Latinoamericana e do Caribe em Ciências da Saúde), sendo acessada através do link disponibilizado pela Biblioteca Virtual de Saúde (BVS), bem como em Sites Rev. Psicol Saúde e Debate. Ago., 2021:7(2): 151-168. 
Governamentais. Buscou-se artigos que abordassem sobre as questões de gênero e sexualidade na educação, sobretudo os desafios e potencialidades acerca do debate do tema nos serviços públicos, sendo selecionados utilizando os seguintes critérios de inclusão: Estudos publicados nas bases de dados anteriormente referidas, publicados entre os anos de 2009 a 2019, apresentados em texto integral, no idioma Português, e cujo o título e/ou resumo fizessem referência à temática dos desafios e potencialidades no debate de gênero e sexualidade.

A pesquisa realizada teve como resultado a identificação de 135 artigos, sendo $129 \mathrm{em}$ base de dados (BVS, Lilacs/BDENF, Scielo) e $6 \mathrm{em}$ bases de dados governamentais, assim como apresentado na Figura 1. Do material obtido, 27 artigos, procedeu-se à leitura minuciosa de cada resumo/artigo, destacando aqueles que responderam ao objetivo proposto por este estudo, a fim de organizar e tabular os dados. Foi realizada uma leitura crítica e reflexiva dos títulos e dos resumos encontrados, e para uma melhor organização e tabulação dos dados, os pesquisadores elaboraram instrumento de coleta de dados contendo: título, ano de publicação, categoria do estudo, natureza do estudo, referencial teórico, método de análise e identificação do tema proposto. Seguindo esses critérios de inclusão, 11 estudos foram selecionados para análise, os quais são referenciados no presente texto. Logo, foram extraídos os conceitos abordados em cada artigo e de interesse dos pesquisadores, que dessa forma resultaram na realização da discussão.

Tabela 1. Processo de busca e seleção dos artigos

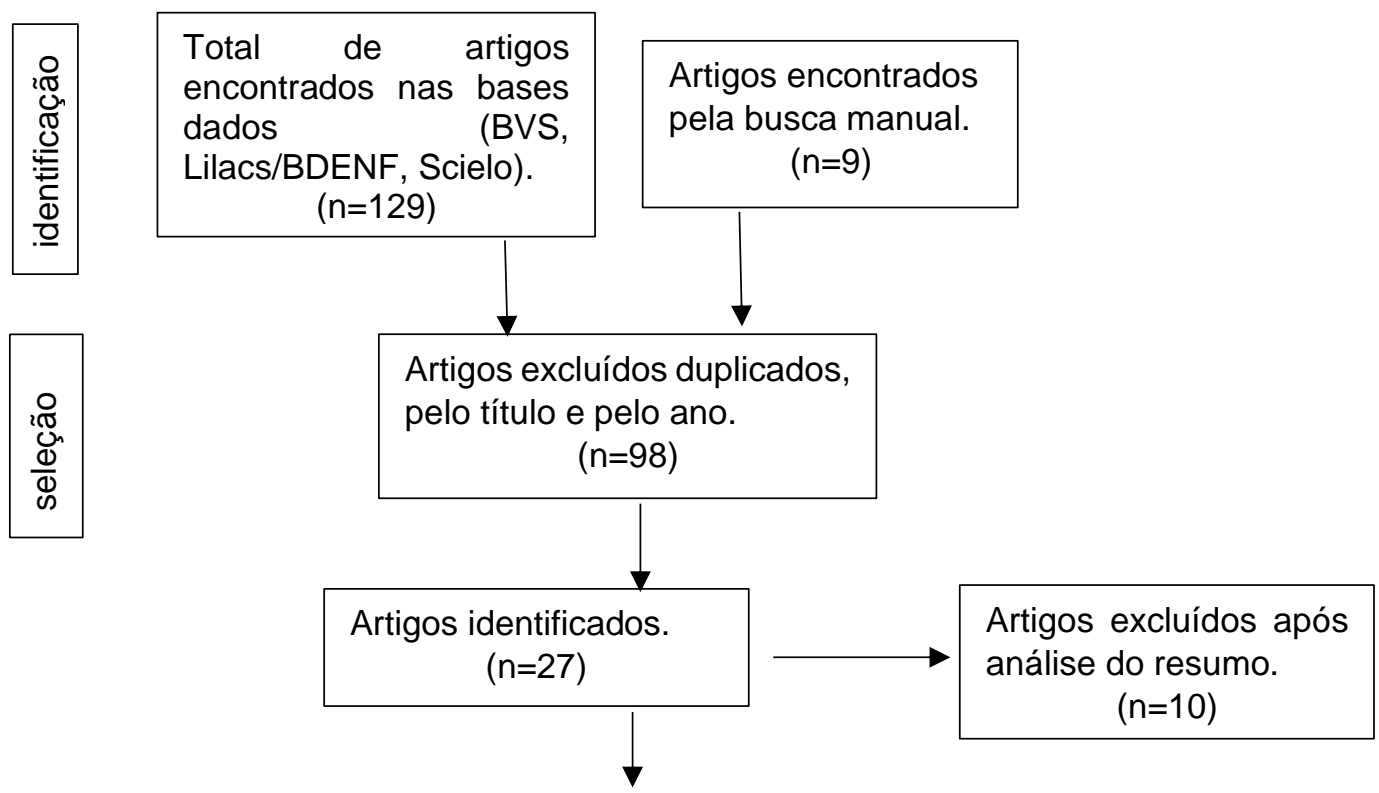

Rev. Psicol Saúde e Debate. Ago., 2021:7(2): 151-168. 


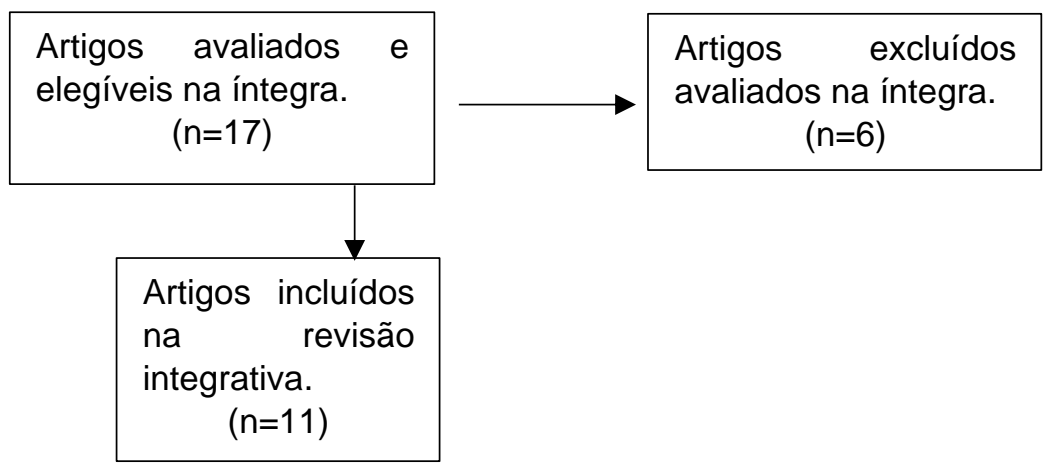

Fonte: Elaborado pelos autores.

\section{RESULTADOS E DISCUSSÃO}

Com o escopo de sistematizar a informação de cada artigo, os dados extraídos dos estudos foram compilados de forma descritiva numa tabela previamente elaborada pelos pesquisadores, facilitando na identificação e reformulação das categorizações temáticas.

A amostra final desta pesquisa foi constituída de 19 textos, sendo, destes, 11 artigos científicos, listados na Tabela 1, 7 documentos governamentais, sendo esses, os Parâmetros Curriculares Nacionais do ensino médio e da 1ํa 4ํㅗ́ie - volume 10 - bem como, a Política Nacional de DST/aids: princípios e diretrizes, o Plano integrado de enfrentamento da feminização da Epidemia de Aids e outras DST, Política Nacional de Atenção Integral à Saúde do Homem e Informação para Tomadores de Decisão da Saúde Pública, bem como um artigo descritivo, não listado, referente ao curso Gênero e Diversidade na escola.

Todos os artigos foram publicados no idioma Português, que por fim foram elencados em uma tabela, assim como apresentada abaixo na Tabela 1, abordando de maneira concisa os objetivos, conclusões e delineamento da pesquisa de cada autor. Concomitantemente, resultou, a partir das evidências científicas encontradas, na apresentação de três temáticas: saúde e gênero: inserção do SUS e políticas públicas; educação e saúde; as implicações de gênero na educação. 
Tabela 2. Resumo dos artigos que constituem a amostra da revisão.

\begin{tabular}{|c|c|c|c|}
\hline $\begin{array}{l}\text { Autor } \\
\text { (Ano) }\end{array}$ & Título & Objetivo & Método \\
\hline $\begin{array}{l}\text { Lionço } \\
\text { (2009) }\end{array}$ & $\begin{array}{l}\text { Atenção integral à } \\
\text { saúde e diversidade } \\
\text { sexual no Processo } \\
\text { Transexualizador do } \\
\text { SUS: avanços, } \\
\text { impasses, desafios. }\end{array}$ & $\begin{array}{l}\text { O artigo tem por objetivo a } \\
\text { consideração crítica dos } \\
\text { avanços, impasses e desafios } \\
\text { na instituição dessa política } \\
\text { pública de saúde, discutindo a } \\
\text { ambivalência no processo de } \\
\text { construção da norma técnica }\end{array}$ & $\begin{array}{l}\text { Metodologia } \\
\text { dialética-crítica }\end{array}$ \\
\hline $\begin{array}{l}\text { Carrara; } \\
\text { Russo; } \\
\text { Faro } \\
(2009)\end{array}$ & $\begin{array}{l}\text { A política de atenção à } \\
\text { saúde do homem no } \\
\text { Brasil: os paradoxos da } \\
\text { medicalização do } \\
\text { corpo masculino }\end{array}$ & $\begin{array}{l}\text { Discutir o modo como o } \\
\text { discurso dos especialistas (no } \\
\text { caso, os médicos urologistas) } \\
\text { se articula ao discurso militante } \\
\text { dos movimentos sociais, tendo } \\
\text { como objetivo a medicalização } \\
\text { do corpo masculino. }\end{array}$ & $\begin{array}{l}\text { Metodologia } \\
\text { dialética-crítica }\end{array}$ \\
\hline $\begin{array}{l}\text { Maia; } \\
\text { Navarro; } \\
\text { Maia A. F } \\
(2011)\end{array}$ & $\begin{array}{l}\text { Relações entre gênero } \\
\text { e escola no discurso de } \\
\text { professoras do ensino } \\
\text { fundamental }\end{array}$ & $\begin{array}{l}\text { Identificar conceitos e opiniões } \\
\text { de professores das séries } \\
\text { iniciais do Ensino Fundamental } \\
\text { sobre a questão do gênero } \\
\text { presente em nossa sociedade } \\
\text { e sua relação com a educação } \\
\text { de crianças no contexto } \\
\text { escolar. }\end{array}$ & Qualitativo \\
\hline
\end{tabular}




\begin{tabular}{|c|c|c|c|}
\hline $\begin{array}{l}\text { Cardoso; } \\
\text { Ferro } \\
(2012)\end{array}$ & $\begin{array}{l}\text { Saúde e população } \\
\text { LGBT: demandas e } \\
\text { especificidades em } \\
\text { questão }\end{array}$ & $\begin{array}{l}\text { A partir da eminente } \\
\text { necessidade de formação dos } \\
\text { agentes da saúde no tema } \\
\text { LGBT, assim como da } \\
\text { elaboração de ações voltadas } \\
\text { para as demandas específicas } \\
\text { dessa população, a intenção do } \\
\text { artigo é contribuir para a } \\
\text { reflexão sobre alguns dos } \\
\text { fatores que podem interferir de } \\
\text { maneira substancial no } \\
\text { processo de saúde da } \\
\text { população LGBT }\end{array}$ & $\begin{array}{l}\text { Metodologia } \\
\text { dialética-crítica }\end{array}$ \\
\hline $\begin{array}{l}\text { Amaro } \\
(2017)\end{array}$ & $\begin{array}{l}\text { Para discutir (ainda } \\
\text { mais) gênero e } \\
\text { sexualidade na escola: } \\
\text { políticas e práticas de } \\
\text { resistências }\end{array}$ & $\begin{array}{l}\text { Problematizar e funcionar } \\
\text { como propulsão aos } \\
\text { deslocamentos e } \\
\text { desalojamentos na perspectiva } \\
\text { de compreendermos que } \\
\text { políticas e práticas se } \\
\text { confrontam e se configuram } \\
\text { nos espaços diversos } \\
\text { formativos. }\end{array}$ & Descritivo \\
\hline $\begin{array}{l}\text { Gomes } \\
\text { (2018). }\end{array}$ & $\begin{array}{l}\text { Gênero, } \\
\text { sexuais e direitos } \\
\text { implicações na saúde }\end{array}$ & $\begin{array}{l}\text { Problematizar aspectos } \\
\text { relacionados a gênero e } \\
\text { direitos sexuais, bem como } \\
\text { suas implicações no campo da } \\
\text { saúde. }\end{array}$ & $\begin{array}{l}\text { Descritivo de } \\
\text { abordagem } \\
\text { qualitativa }\end{array}$ \\
\hline
\end{tabular}




\begin{tabular}{|c|c|c|c|}
\hline $\begin{array}{l}\text { Silva; } \\
\text { Borba } \\
\text { (2018). }\end{array}$ & $\begin{array}{l}\text { Encontros com a } \\
\text { diferença na formação } \\
\text { de profissionais de } \\
\text { saúde: juventudes, } \\
\text { sexualidades } \\
\text { gêneros na escola }\end{array}$ & $\begin{array}{l}\text { Discutir a forma como gênero e } \\
\text { sexualidades são significados } \\
\text { por jovens estudantes de } \\
\text { escolas públicas do ensino } \\
\text { médio da cidade de Santos, } \\
\text { localizada no litoral sul do } \\
\text { estado de São Paulo. }\end{array}$ & Qualitativa \\
\hline $\begin{array}{l}\text { Auad; } \\
\text { Ramos; } \\
\text { Salvador; } \\
(2018)\end{array}$ & $\begin{array}{l}\text { Educação, } \\
\text { emancipação e } \\
\text { feminismos possíveis: } \\
\text { um olhar histórico } \\
\text { sobre a igualdade de } \\
\text { gênero na escola }\end{array}$ & $\begin{array}{l}\text { Debater dados históricos sobre } \\
\text { a trajetória educacional das } \\
\text { mulheres no Brasil, desde o } \\
\text { século XIX, de modo a } \\
\text { contextualizar um conjunto de } \\
\text { fenômenos, como a } \\
\text { denominada feminização do } \\
\text { magistério. }\end{array}$ & Descritivo \\
\hline $\begin{array}{l}\text { Preuss; } \\
\text { Martins } \\
\text { (2019). }\end{array}$ & $\begin{array}{l}\text { Reflexões acerca da } \\
\text { Política Nacional de } \\
\text { Saúde Integral LGBT } \\
\text { nas regiões de } \\
\text { fronteiras }\end{array}$ & $\begin{array}{l}\text { O artigo tem por objetivo a } \\
\text { consideração crítica dos } \\
\text { avanços, impasses e desafios } \\
\text { na instituição dessa política } \\
\text { pública de saúde, discutindo a } \\
\text { ambivalência no processo de } \\
\text { construção da norma técnica }\end{array}$ & $\begin{array}{l}\text { Metodologia } \\
\text { dialética-crítica }\end{array}$ \\
\hline $\begin{array}{l}\text { Ferraz; } \\
\text { Addor; } \\
\text { Neto } \\
(2019)\end{array}$ & $\begin{array}{l}\text { Políticas públicas de } \\
\text { gênero na educação: } \\
\text { uma análise para o } \\
\text { desenvolvimento }\end{array}$ & $\begin{array}{l}\text { Discutir o modo como o } \\
\text { discurso dos especialistas (no } \\
\text { caso, os médicos urologistas) } \\
\text { se articula ao discurso militante } \\
\text { dos movimentos sociais, tendo } \\
\text { como objetivo a medicalização } \\
\text { do corpo masculino. }\end{array}$ & $\begin{array}{l}\text { Metodologia } \\
\text { dialética-crítica }\end{array}$ \\
\hline
\end{tabular}




\begin{tabular}{|l|l|l|l|} 
Silva & Caminhos possíveis & Identificar conceitos e opiniões & Qualitativo \\
para produção de & de professores das séries \\
práticas pedagógicas & iniciais do Ensino Fundamental \\
no enfrentamento das & sobre a questão do gênero \\
violências de gênero e & presente em nossa sociedade \\
sexualidade & $\begin{array}{l}\text { e sua relação com a educação } \\
\text { de crianças no contexto } \\
\text { escolar. }\end{array}$ & \\
\hline
\end{tabular}

Fonte: elaborado pelos autores.

\section{Saúde e gênero: inserção do SUS e políticas públicas}

No cenário brasileiro atual, as políticas públicas podem ser definidas como respostas do Estado a problemas que emergem na sociedade. Nesse viés, Lucchese (2004) afirma que o campo da ação social que abrange as políticas públicas de saúde, têm a função de definir as respostas do Estado às necessidades básicas de saúde da população em geral, com o escopo de operacionalizar ações de promoção, proteção e recuperação da saúde em nível individual e coletivo.

Nesse cenário, estabelecendo a saúde como um direito universal e sendo dever do Estado prover o acesso à saúde a todos os cidadãos e cidadãs, o SUS emerge da luta do Movimento da Reforma Sanitária, sobretudo, no período de redemocratização do país, indo de encontro às políticas vigentes na época pós-sus, altamente hegemônicas. A Saúde, a Previdência e a Assistência Social integram o Sistema de Seguridade Social e esta conquista representa o compromisso e a responsabilidade do Estado com o bemestar da população (Brasil, 1998).

Nessa perspectiva, o sistema ainda apresenta inúmeros desafios, sobretudo a construção de uma política pública de saúde universal, perspectiva que engloba todos os setores existentes na sociedade, tendo como principal objetivo a criação de maneiras adequadas para a conter as problemáticas vigentes. Para tal, é crucial a participação efetiva dos diversos setores segmentais da sociedade no desenvolvimento da efetivação e implementação dessas políticas. 
A dimensão de gênero tem-se inserido nas políticas públicas do setor de diversas maneiras, sobretudo, durante esses últimos anos da incorporação do Sistema único de Saúde. Nesse sentido, de maneira alegórica no cenário atual do SUS, considera-se, de forma geral, tais políticas inerentes ao exposto: a política de IST e aids, com destaque para o Plano Integrado de Enfrentamento da Feminização da Epidemia de Aids e Outras IST (Brasil, 2007), a Política Nacional de Atenção Integral à Saúde do Homem (Brasil, 2008) e a Política de Atenção Integral à Saúde da População LGBT (Brasil, 2009).

Os agravos à saúde da comunidade LGBT, são determinados socialmente, e segundo Lionço (2009), esses paradigmas são observados, sobretudo em consequência das inúmeras violações dos direitos determinados à essas pessoas. Nesse aspecto, conforme Cardoso e Ferro (2012), essa população específica, por não se adequar a um padrão heteronormativo, acaba por ter direitos básicos agredidos, levando em consideração que diversos fatores os colocam em condição de vulnerabilidade, como a violação do direito à saúde - um direito social garantido por lei, e sem dúvidas, crucial.

A Política Nacional de Saúde Integral da População LGBT possui como marca o reconhecimento dos efeitos da discriminação e do preconceito no processo de saúdedoença dessa população. Contudo, se percebe a ausência da construção e divulgação de estudos sistemáticos e regulares voltados para a ação desses efeitos contra essa população (Gomes, Facchini, \& Meneghel, 2018).

Nesse contexto, a integralidade dessa política deixa evidente as ações transversais em diversas áreas da saúde como: a inserção da temática da atenção integral à população LGBT na formação permanente dos profissionais do SUS; a inclusão de quesitos orientação sexual, identidade de gênero e étnico-racial nos documentos de notificação de violência da Secretaria de Vigilância em Saúde (SVS); a sensibilização dos profissionais de saúde acerca das especificidades da população LGBT.

Ademais, é crucial destacar a discussão da política de IST, na abordagem das relações de gênero, sexualidade e saúde. Em termos de saúde, houve uma eclosão do movimento homossexual e sua visibilidade a partir do surgimento do vírus HIV/Aids, que era predominantemente associado a esse segmento específico. Estes eram denominados grupos de risco e foram considerados, de modo geral, responsáveis pela proliferação do vírus no país (Preuss \& Martins, 2019). 
Nessa condição, a epidemia trazia um conjunto de questões interseccionais, que ia além do campo da saúde. Assim, a política não se limitaria às recomendações básicas (mas necessárias) ao uso de preservativos, por exemplo, mas precisou ampliar as medidas que reconhecessem e construísse os instrumentos para trabalhar com relações desiguais e vulneráveis que presenciamos no cotidiano, em princípio desigualdades de gênero.

Por sua vez, a proposta de enfrentamento da feminização da epidemia do HIV/aids tem como eixo de referência a mobilização da sociedade em relação aos direitos políticos, sociais, econômicos e reprodutivos das mulheres e sua aplicação compreende a articulação com estados, municípios e sociedade civil (Brasil, 2007). Com o escopo de instituir e fortalecer medidas e ações de enfrentamento à violência contra as mulheres seja ela física, psicológica ou sexual.

Ainda, tratando-se de políticas públicas com enfoque de gênero, a Política Nacional de Atenção Integral à Saúde do Homem representou um marco importante nas discussões acerca da carência de políticas que abordassem a população especificamente masculina. Nessa perspectiva, a saúde do homem surgiu como tema no campo de estudos do país a partir da década de 1970, com os primeiros debates a despeito da relação entre o modelo de masculinidade hegemônico na sociedade e os agravos à saúde do homem (Gomes \& Nascimento, 2006).

Com isso, é fundamental destacar que uma das maiores preocupações desta política é, além da promoção do acesso da população masculina aos serviços de atenção primária à saúde, mas também que a população masculina passa a reconhecer sua fragilidade e vulnerabilidade, para que possa compreender e assumir sua demanda (Carrara, Russo, \& Faro, 2009).

A Política Nacional de Atenção Integral à Saúde do Homem estabelece, então, como seu objetivo principal:

Promover a melhoria das condições de saúde da população masculina do Brasil, contribuindo, de modo efetivo, para a redução da morbidade e mortalidade dessa população, através do enfrentamento racional dos fatores de risco e mediante a facilitação ao acesso, às ações e aos serviços de assistência integral à saúde. (Brasil, 2008, p.31).

Ademais, a política afirma, nesse sentido, princípios consonantes aos do SUS relacionados, por exemplo, à humanização, qualidade de vida e promoção da Rev. Psicol Saúde e Debate. Ago., 2021:7(2): 151-168. 
integralidade do cuidado na população masculina promovendo o reconhecimento e respeito à ética e aos direitos do homem, obedecendo às suas peculiaridades socioculturais (Brasil, 2008).

\section{Sexualidade e saúde no âmbito escolar}

Tratando-se do cenário das políticas públicas, o Brasil, possui ainda certas insuficiências, inclusive no quesito de programas e ações de saúde e educação que cinjam com exclusividade a seara populacional que é definida como adolescência e juventude. Nesse sentido, para que adversidades como essas sejam solucionadas é de imensa importância inserir no contexto escolar práticas educacionais que além de promover saúde possam perpassar por assuntos como sexualidade e gênero, já que esse ambiente é onde jovens e adolescentes constroem seus vínculos sócio afetivos.

Porém, os meios metodológicos de inclusão de pautas no âmbito escolar destacam-se as oficinas, que, apesar de se reconhecer sua importância como alternativa à simples transmissão de informação, não apresenta caráter político, o que impede a criação de questionamentos e debates, bem como a participação ativa dos jovens e adolescentes no processo.

Sendo que, essa ferramenta poderia ser usada de forma politizada, percebendo como a saúde e a educação perpassam os campos históricos e sociais, com o objetivo de estimular o questionamento, os debates e as trocas e informações considerando a vivência de cada estudante. E para além disso, fazer com eles possam reproduzi-las nos ambientes extraescolares.

A articulação entre saúde e educação deve respeitar a realidade $e$ as particularidades do ambiente escolar. Porém, à medida que, essa discussão é colocada sobre a responsabilidade apenas de profissionais da saúde, como explicado por Catharino:

Contém o risco de fracionar o trabalho pedagógico, colocando nas mãos de 'especialistas' alheios ao cotidiano escolar, uma atividade que diz respeito às formas de relação, aos discursos, aos jogos de poder e às trocas afetivas que são produzidos naquela comunidade (2006, p. 7).

Ao inserir a problematização de gênero e sexualidade no ambiente escolar, permite-se o compartilhamento de percepções, corroborando para o processo de 
aprendizagem, bem como possibilita a abertura para novos debates e construções (Silva \& Borba, 2018).

Por isso, que é destaca uma maior necessidade de se incluir esses discursos no ambiente escolar, respeitando a individualidade de cada adolescente, o que poderá ser alcançado com a maior participação dos discentes, permitindo o protagonismo destes, estimulando que eles apontem as questões a serem discutidas, à medida que o debate é direcionado para eles.

Ademais, como apontado por Catharino (2006), esses jovens consideram o ambiente escolar como local de liberdade para se discutir a sexualidade, podendo questionar os mitos e tabus sociais. Algo que, não deve ser apenas considerado, mas também valorizado, de maneira que, os esforços para a inclusão desses debates no âmbito escolar devem estar voltados para essa confiança.

Dessa forma, podendo se comprometer com efetivação da promoção da saúde integral, desconstruindo comportamentos normatizados e regras construídas através de gênero e das relações de poder, com isso, levando em conta as diversidades e singularidades sociais e históricas.

\section{As implicações de gênero na educação}

O conceito de gênero surge em meio ao movimento social feminista, no século XX, a partir da percepção de que a mulher era tida como um sujeito invisível social e academicamente. Logo, essa discussão entra como uma forma de compreender e modificar o que se entendia por ser mulher, sendo, uns dos primeiros pontos a serem discutidos são os fatores que levam à opressão feminina (Catharino, 2006).

Para o senso comum, gênero é apenas o binário homem e mulher, sendo que existe uma enorme ramificação, pelo fato de ser a forma como um ser humano se identifica, não podendo se ater apenas ao sexo biológico. Porém, é difícil trazer essa discussão para dentro de uma sociedade que já possui preconceitos e discriminação com essa diversidade que acompanha as identidades de gênero.

Com isso, Silva (2019) descreve como e porque a escola está relacionada a esta discussão, ao ponto que é uma instituição social responsável por propagar e difundir conhecimentos. Logo, não apenas reproduz a lógica hegemônica de gênero, como legítima essa desigualdade. A escola é o primeiro ambiente em que se percebe essa 
segregação entre meninos e meninas, o que além de restringir as atividades de cada gênero, perpetua ideias de divisão que só fazem sentido no âmbito escolar.

Não se atribui apenas à escola a responsabilidade da construção desse conceito dicotômico de gênero e nem a vê como a criadora, é algo que não depende apenas de uma secção da sociedade. Contudo, é preciso reconhecer que suas proposições, imposições e proibições produzem um sentido de verdade (Silva, 2019). Em que, pouco se percebe a ação das escolas para tentar romper com essa construção social sobre cada gênero.

Um dos desafios apontados por Silva (2019) foi a dificuldade e relutância dos profissionais de em abordar em sala de aula temas relacionados a gênero e a sexualidade, em que, por exemplo, alguns profissionais se escondiam em discursos de não saber como abordar sobre gênero em sala de aula, como forma de distanciamento seguro. Bem como, não viam a escola como responsável para tratar as questões de gênero (Maia, Navarro, \& Maia, 2011).

Outros relatos afirmam que em meio a essa dificuldade em abordar sobre gênero, docentes utilizavam-se de situações que ocorriam em sala de aula, como discussões e ofensas entre alunos, para poderem começar a introduzir essa discussão dentro da escola (Silva, 2019).

Além disso, é destacado que a principal estratégia utilizada pelos professores, para discutir sobre gênero, é a de levantar questionamentos a partir das ideias dos estudantes (Silva, 2019). De modo que, desestabiliza o que os alunos entendem como normal. Silva (2019) define melhor essa metodologia, caracterizando sua complexidade, mas também sua amplitude:

Devido ao caráter complexo e amplo que essa estratégia passa a ocupar na prática pedagógica dessas professoras, podemos caracterizá-la como uma pedagogia do questionamento, que abarca mais do que a metodologia desenvolvida em aulas, mas passa a se configurar como uma forma de compreender os objetivos de se trabalhar com as noções de diferença e diversidade (p. 438).

Catharino (2006), descreve a necessidade de se reconhecer o caráter político que gênero apresenta, ao ponto em que é enfatizado a construção social e histórica a partir da diversidade desse. Tal fator admite as relações sociais como contribuintes para a 
formação da identidade de gênero, o que, para a autora, pode até certo ponto tornar o conceito de gênero relativo.

Contudo, essa abordagem permite o reconhecimento da pluralidade e multiplicidade da identidade de gênero. Com isso, pode-se reconhecer a escola como um terreno mais propício para a construção do desenvolvimento de diálogos e acúmulos sobre gênero, ao passo que a mesma apresenta caráter de formação, em que o indivíduo transita em vários momentos da vida, seja como discente, docente ou responsável pelo discente (Auad, Ramos, \& Salvador, 2018)

Ao responder à questão do estudo, os autores identificaram que uma parcela do corpo docente brasileiro já percebeu a necessidade de se discutir gênero dentro das escolas, de modo que alguns já conseguem inserir levemente esse discurso em sala de aula, elaborando estratégias e metodologias de forma que esse diálogo possa ser levantado e construído no ambiente escolar. Porém, o senso comum ainda prevalece na sociedade, o que é aproveitado pelas instituições de ensino como forma de adiar o começo dessa discussão - sendo este um debate inevitável. Com isso, colaborando para a imposição da normalidade da segregação de gênero, perpetuando preconceitos e discriminações.

\section{CONSIDERAÇÕES FINAIS}

Em virtude da revisão realizada, evidencia-se que ainda existem inúmeros entraves relacionados aos direitos e garantias das relações de gênero na saúde e educação. Entretanto, compreende-se a existência de avanços significativos no campo político, sobretudo, por esforços de movimentos sociais em virtude da garantia da promoção e proteção desses direitos garantidos pela lei maior do país, relacionados às políticas integrais da população LGBTQIA+, e enfrentamento às desigualdades de gênero nos serviços públicos.

Destarte, os resultados desses estudos já realizados, decorrem na interpretação de que os desafios e potencialidades no debate de gênero e sexualidade tornam-se ainda um empecilho e deixa perceptível que há uma necessidade, sobretudo em tempos de retrocessos, do debate de gênero dentro das instituições de ensino, o que passa a 
ser um papel crucial para o enfrentamento das desigualdades, corroborando para a construção de potencialidades significativas na inserção desse discurso na sociedade.

\section{REFERÊNCIAS}

Amaro, I. (2017). Para discutir (ainda mais) gênero e sexualidade na escola: políticas e práticas de resistências. Periferia, 9 (2), 5-15. doi: 10.12957.2017.31277.

Auad, D. Ramos, M.R.N \& Salvador, R. (2017). Educação, emancipação e feminismos possíveis: um olhar histórico sobre a igualdade de gênero na escola. Revista educação e emancipação, 10 (4), 186-208. doi: 10.18764/2358-4319.

Constituição da República Federativa do Brasil. (1988). Brasília. Recuperado em 04 abril 2020 ,

de https://www2.senado.leg.br/bdsf/bitstream/handle/id/518231/CF88_Livro_EC91_2016.p df.

Ministério da saúde. (2007). Plano integrado de enfrentamento da feminização da epidemia de aids e outras dst. Coordenação nacional de DST e AIDS. Brasília, DF: Ministério da Saúde.

Ministério da Saúde. (2008). Política nacional de atenção integral à saúde do homem. Secretaria de atenção à saúde. Brasília, DF: Ministério da Saúde.

Ministério da Saúde. (2009). Política nacional de saúde integral de lésbicas, gays, bissexuais, travestis e transexuais. Brasília, DF: Ministério da Saúde.

Cardoso, M.R., \& Ferro, L.F. (2012). Saúde e população LGBT: demandas e especificidades em questão. Psicologia Ciência e Profissão, 32 (3), 552-563. doi: 10.1590/S1414-98932012000300003.

Carrara, S., Russo, J.A., \& Faro, L. (2009). A política de atenção à saúde do homem no Brasil: os paradoxos da medicalização do corpo masculino. Physis, 19 (3), 659-678. doi: 10.1590/S0103-73312009000300006.

Catharino, T.R. (2006). Gênero e sexualidade no espaço escolar - uma proposta de educação e saúde. Revista Ártemis - Estudos de Gênero, Feminismos e Sexualidades, (5). Recuperado de https://periodicos.ufpb.br/index.php/artemis/article/view/2162.

Ferraz, M.O.K., Addor, N., \& Neto, J.O.N. (2019). Políticas públicas de gênero na educação: uma análise para o desenvolvimento. Revista Eletrônica Do Curso De Direito Da Ufsm, 14 (3). doi: https://doi.org/10.5902/1981369431721

Gomes, R., Murta, D., Facchini, R., \& Meneghel, S.N. (2006). Gênero, direitos sexuais e suas implicações na saúde. Ciênc. saúde coletiva, 23 (6), 1997-2006. DOI: 10.1590/1413-81232018236.04872018.

Gomes, R., \& Nascimento, E.F. (2006). A produção do conhecimento da saúde pública sobre a relação homem-saúde: uma revisão bibliográfica. Cad. Saúde Pública, 22(5), 901-911. doi: 0.1590/S0102-311X2006000500003.

Lionço, T. (2009). Atenção integral à saúde e diversidade sexual no Processo Transexualizador do SUS: avanços, impasses, desafios. Physis: revista de saúde coletiva, 19(1), 43-63, 2009. doi: https://doi.org/10.1590/S0103-73312009000100004.

Lucchese, T.R., Aguiar, D.S., Wargas, T. Lima., L.D. Magalhães, R., \& Monerat, G.L. (2004). Políticas públicas em Saúde Pública. 1a ed. São Paulo/SP. Editora Espaço da Gestão.

Maia, A.C.B., Navarro, C., \& Maia, A.F. (2011). Relações entre gênero e escola no discurso de professoras do ensino fundamental. Psicologia da Educação, (32), 25-46. Rev. Psicol Saúde e Debate. Ago., 2021:7(2): 151-168. 
Recuperado

$$
\text { em }
$$

04

de

abril

de

http://pepsic.bvsalud.org/scielo.php?script=sci_arttext\&pid=S1414-

$69752011000100003 \&$ Ing=pt\&tlng=pt.

Preuss, L.T, Martins, D.A.B. (2019). Reflexões acerca da Política Nacional de Saúde Integral LGBT nas regiões de fronteiras. Interações (Campo Grande), 20(3), 933-946. Recuperado em 04 de abril de 2020, de <http://www.scielo.br/scielo.php?script=sci_arttext\&pid=S1518$70122019000300933 \&$ Ing $=$ en\&nrm=iso $>$.

Scott, J. (1995). Gênero: uma categoria útil de análise histórica. Educação e Realidade, 20(2), 71-99.

Silva, C.G., \& Borba, P.L. (2018). Encontros com a diferença na formação de profissionais de saúde: juventudes, sexualidades e gêneros na escola. Saúde e sociedade. 27(4), 1134-1146. doi: 10.1590/S0104-12902018170274.

Silva, D. (2019). Caminhos possíveis para produção de práticas pedagógicas no enfrentamento das violências de gênero e sexualidade. Periferia, 11(2), 424-441. doi: 10.12957.2019.36363. 